\title{
Ranibizumab in the treatment of patients with visual impairment due to diabetic macular edema
}

This article was published in the following Dove Press journal:

Clinical Ophthalmology

I2 September 201 I

Number of times this article has been viewed

\author{
Francesco Bandello' \\ Umberto De Benedetto' \\ Karl Anders Knutsson' \\ Maurizio Battaglia Parodi' \\ Maria Lucia Cascavilla' \\ Pierluigi lacono 2 \\ 'Department of Ophthalmology, \\ University Vita-salute, Scientific \\ Institute San Raffaele, Milan, \\ Italy; ${ }^{2}$ Fondazione G B Bietti per \\ I'Oftalmologia, IRCCS, Rome, Italy
}

\begin{abstract}
Diabetic macular edema is the major cause of visual acuity impairment in diabetic patients. The exact etiopathogenesis is unknown and, currently, grid/focal retinal laser photocoagulation represents the recommended treatment. It has been demonstrated that vascular endothelial growth factor (VEGF) plays a key role in the pathogenesis of diabetic macular edema by mediating vascular permeability and accumulation of intracellular and extracellular fluid, and thereby represents an appealing candidate as a therapeutic target for the treatment of diabetic macular edema. The advent of intravitreal anti-VEGF drugs has opened up a new era for the management of diabetic macular edema. At present, three anti-VEGF substances are available for routine clinical use, ie, pegaptanib, ranibizumab, and bevacizumab. The aim of this review is to summarize the evidence supporting the use of ranibizumab in clinical practice. Most of the studies analyzed in this review are prospective, controlled clinical trials that have focused on documenting the therapeutic effect of ranibizumab and its safety, providing encouraging results.
\end{abstract}

Keywords: ranibizumab, diabetic macular edema, anti-VEGF, diabetic macular edema

\section{Introduction}

Diabetic macular edema is generally defined as retinal thickening or the presence of hard exudates within one disk diameter from the center of the macula secondary to diabetic retinopathy. ${ }^{1,2}$ It is the major cause of visual acuity impairment in diabetic patients, ${ }^{3}$ and the exact etiopathogenesis remains unknown. Currently, retinal laser photocoagulation is the recommended treatment for clinically significant diabetic macular edema because it is the only treatment supported by a large clinical randomized, controlled trial. ${ }^{4}$ Nevertheless, laser treatment has a limited effect, resulting in functional improvement and anatomical regression of diabetic macular edema in a subset of patients.

Recently, many authors have stressed the role that vascular endothelial growth factor (VEGF) plays in promoting vascular permeability and accumulation of intracellular and extracellular fluid by disrupting the intercellular tight junctions normally present between retinal endothelial cells. ${ }^{5-10}$

Different molecules involved in the pathway of VEGF transcription and activation are being tested or are available for routine clinical use. Three anti-VEGF drugs are currently available for routine clinical use, ie, pegaptanib, ranibizumab, and bevacizumab. New interesting therapeutic approaches are represented by the administration of bevasiranib or rapamycin. The aim of this review is to discuss the published data regarding intravitreal ranibizumab in the treatment of diabetic macular edema.
Correspondence: Umberto De Benedetto Department of Ophthalmology, University Vita-Salute, Scientific Institute San Raffaele, Via Olgettina,

60,20132 , Milan, Italy Tel +3902 26432648

Fax +3902 26433643

Email debenedetto.umberto@hsr.it 


\section{Ranibizumab}

Ranibizumab is an antigen-binding fragment derived from a humanized anti-VEGF antibody that inhibits all biologically active isoforms and active proteolytic fragments of VEGF-A. Many clinical investigations have demonstrated the efficacy of ranibizumab in the treatment of diabetic macular edema.

\section{Initial studies}

Chun et al reported the first pilot study exploring the effects of two dosing regimens of ranibizumab in eyes affected by clinically significant diabetic macular edema. ${ }^{11}$ Ten patients were enrolled, with five receiving ranibizumab $0.3 \mathrm{mg}$ and five receiving ranibizumab $0.5 \mathrm{mg}$ at baseline and at one and two months. All patients completed the 24-month follow-up period. At month 3, 40\% of patients gained more than 15 letters, $50 \%$ gained more than 10 letters, and $80 \%$ obtained an improvement of at least one letter in best corrected visual acuity (BCVA). After three months, the mean decrease in central retinal thickness was $45.3 \mu \mathrm{m}$ and $197.8 \mu \mathrm{m}$ in the low-dose group and high-dose group, respectively. Intravitreal injections of ranibizumab were generally well tolerated, and no systemic adverse events were reported.

Nguyen et al investigated the role of ranibizumab in diabetic macular edema in a nonrandomized study. ${ }^{12}$ Ten patients with chronic diabetic macular edema received intraocular injections of $0.5 \mathrm{mg}$ of ranibizumab at baseline and at one, two, four, and six months. A dose of $0.5 \mathrm{mg}$ was chosen because it was the highest dose available and had documented safety. The main outcomes measured were changes in BCVA and central retinal thickness, as assessed by optical coherence tomography measurement at the sevenmonth examination. Compared with baseline, mean foveal thickness showed a meaningful reduction, decreasing from $503 \mu \mathrm{m}$ to $257 \mu \mathrm{m}$, with a reduction of $85 \%$ of the excess foveal thickness present at baseline. At the nine-month visit, there was a worsening of diabetic macular edema compared with the seven-month visit, but retinal thickness did not return to baseline levels. The authors did not expect improvement of visual function in the selected patients because of the chronicity of diabetic macular edema and because the patients enrolled were characterized by lack of response to other treatments. However, the mean and median values of BCVA improved at seven months by 12.3 and 11 letters, respectively. Improvement in foveal thickening correlated with improvement in visual acuity at each study visit. The injections were well tolerated with no ocular or systemic adverse events.

\section{READ-2 study}

More recently, the results of the READ-2 study were published. READ-2 is a prospective, randomized, interventional, multicenter clinical trial designed to compare ranibizumab with focal/grid laser, alone or in combination, for the treatment of diabetic macular edema. ${ }^{13,14}$ One hundred and twenty-six patients were randomized to receive $0.5 \mathrm{mg}$ of ranibizumab, focal/grid laser photocoagulation, or a combination of $0.5 \mathrm{mg}$ of ranibizumab and focal/grid laser. In the ranibizumab group, 42 patients received $0.5 \mathrm{mg}$ at baseline and months 1, 3, and 5. In the laser group, 42 patients received focal/grid laser photocoagulation at baseline and month 3 if needed (center subfield thickness was $>250 \mu \mathrm{m}$ ). In the combined therapy group, 42 patients received a combination of $0.5 \mathrm{mg}$ of ranibizumab and focal/ grid laser at baseline and month 3 . The primary outcome was the change in BCVA at month 6 in comparison with baseline values. After six months, the ranibizumab group showed a significant improvement in mean BCVA compared with patients receiving focal/grid laser. BCVA in the group receiving combined therapy was not statistically different from the first two groups. A resolution of 50\%, $33 \%$, and $45 \%$ of excess foveal thickening was documented in the ranibizumab, laser, and combined therapy groups, respectively. After six months, for the two years of follow-up, if retreatment criteria were met, all subjects could be treated with ranibizumab. In the ranibizumab group, BCVA improved from 7.4 letters at six-month follow-up to 7.7 letters at the end of the 24-month follow-up. The laser group improved BCVA from 0.5 letters to 5.1 letters at the end of follow-up, and the combined therapy group patients showed an improvement in BCVA of 6.8 letters at month 24, compared with 3.8 letters in the same patients at month 6 . These data demonstrate that intravitreal ranibizumab is effective in the treatment of recurrent and persistent diabetic macular edema and that the improvement of visual acuity could be maintained during a follow-up of two years. This study also showed that ranibizumab is associated with significant improvement in patients who previously received only laser photocoagulation.

Finally, this study demonstrates that intravitreal injections combined with laser treatment are effective in reducing the frequency of injections without impairment of visual acuity at the end of two years of follow-up. Indeed, the mean number of injections was 9.3, 4.4, and 2.9 in the ranibizumab, laser, and combined therapy groups, out of a maximum of 13, nine, and six possible injections, respectively. 


\section{RISE and RIDE studies}

RISE and RIDE are Phase III, double-masked, multicenter, randomized, sham injection-controlled studies evaluating the efficacy and safety of ranibizumab injections in patients with diabetic macular edema. ${ }^{15}$ Recruited patients were randomized into three groups, ie, sham injections, ranibizumab $0.3 \mathrm{mg}$ injections, and ranibizumab $0.5 \mathrm{mg}$ injections. The primary outcomes assessed were the proportion of subjects who gain at least 15 letters in BCVA compared with baseline, mean change from baseline in BCVA, and mean change from baseline in central foveal thickness. The preliminary results show that patients gaining at least three lines compared with baseline were $18.1 \%, 44.8 \%$, and $39.2 \%$ in the RISE study and $12.3 \%, 33.6 \%$, and $45.7 \%$ in the RIDE study in the sham, $0.3 \mathrm{mg}$ ranibizumab, and $0.5 \mathrm{mg}$ ranibizumab groups, respectively. Subjects achieving a visual acuity of at least $20 / 40$ were $37.8 \%, 60 \%$, and $63.2 \%$ in the RISE study, and $34.6 \%, 54.4 \%$, and $62.2 \%$ in the RIDE study in the sham, $0.3 \mathrm{mg}$ ranibizumab, and $0.5 \mathrm{mg}$ ranibizumab groups, respectively. An analysis of the 24-month data from the two studies showed an ocular and general safety profile similar to previous trials, with no adverse effects due to ranibizumab injections.

\section{RESOLVE study}

RESOLVE is a randomized, double-masked, multicenter, Phase II study assessing the safety and efficacy of two concentrations of ranibizumab compared with nontreatment control for the treatment of diabetic macular edema in 151 patients with clinically significant diabetic macular edema. Patients with a central macular thickness of $300 \mu \mathrm{m}$ or greater were randomized to receive three-monthly intravitreal injections with either $0.3 \mathrm{mg}$ or $0.5 \mathrm{mg}$ ranibizumab, or placebo. After the three-monthly intravitreal injections, treatment was administered on an as-needed basis for nine months. The primary endpoint was the change in visual function at the end of follow-up. The study design allowed the investigator to double the dose of ranibizumab if resolution of macular edema was incomplete after one month. Moreover, retinal photocoagulation could be administered if needed. ${ }^{16,17}$ During the 12 months of follow-up, mean BCVA increased and mean central retinal thickness decreased continuously over time. Mean change in BCVA from baseline to the 12-month examination was -1.4 letters in the sham group. The groups receiving ranibizumab gained 10.3 letters. The proportion of patients who gained $\geq 10$ letters and $\geq 15$ letters was three-fold higher in the ranibizumab arm compared with the sham arm. Mean change in central retinal thickness from baseline to month 12 was significantly higher in the ranibizumab group with respect to the sham group $(-194.2 \mu \mathrm{m}$ versus $-48.4 \mu \mathrm{m}$, respectively, $P<0.0001)$. Safety data were consistent with previous studies of intravitreal ranibizumab. The mean number of injections administered during 12 months was 10.2 and 8.9 for ranibizumab and sham, respectively.

\section{RESTORE study}

Focal or grid laser is currently considered the standard of care in diabetic macular edema. The RESTORE study ${ }^{18}$ enrolled 345 patients affected by diabetic macular edema to compare the effects secondary to laser treatment, ranibizumab injections, or combination of the two treatments. All patients were randomized to three groups, ie, ranibizumab and sham laser $(\mathrm{n}=116)$, ranibizumab and laser photocoagulation $(\mathrm{n}=118)$, or sham injections and laser $(\mathrm{n}=111)$. Patients received three initial consecutive monthly injections followed by other injections on a prn basis, and laser/sham laser was performed at baseline. Retreatments were given in accordance with Early Treatment Diabetic Retinopathy Study (ETDRS) guidelines at intervals no shorter than three months from the previous treatment if considered necessary by the investigator. After 12 months, a significantly greater proportion of patients had a BCVA letter score $\geq 15$ and BCVA letter score level $>73$ (20/40 Snellen equivalent) with ranibizumab (22.6\% and 53\%, respectively) and ranibizumab + laser (22.9\% and $44.9 \%)$ versus laser alone $(8.2 \%$ and $23.6 \%)$. Similar results could be found evaluating fluorescein angiography. A significantly larger proportion of patients who underwent ranibizumab injections alone or ranibizumab injections associated with laser treatment obtained total resolution of leakage compared with the laser group (19.4\% and $13.7 \%$ versus $2.2 \%$ ). Additionally, the mean central retinal thickness changed significantly at the 12-month follow-up $(118.7 \mu \mathrm{m}, P=0.0002$ and $128.3 \mu \mathrm{m}, P<0.0001$ in the first two groups versus $61.3 \mu \mathrm{m}$ in the laser group). At one year of follow-up, no significant differences were detected between ranibizumab monotherapy and ranibizumab associated with laser photocoagulation. No cases of endophthalmitis occurred, and the patients who underwent ranibizumab treatment did not have an increased risk of cardiovascular or cerebrovascular events in this study. Between months 3 and 11, patients received an average of 4.1 ranibizumab intravitreal injections in the ranibizumab arm, 3.8 in the ranibizumab + laser arm, and 4.5 sham injections in the laser-treated arm. 


\section{DRCRnet study}

It is well known that corticosteroids may also play an important role in reducing diabetic macular edema ${ }^{19,20}$ by decreasing the release of arachidonic acid derivates, such as prostaglandins, that are responsible for altered retinal vascular permeability and inhibition of VEGF production.

The Diabetic Retinopathy Clinical Research Network (DRCRnet) has designed a randomized, multicenter clinical trial to confirm the role of steroids and anti-VEGF drugs to compare these new forms of treatment with conventional laser. $^{21,22}$ The study (with two years of follow-up) enrolled 691 patients and examined a total of 854 eyes randomized into four groups receiving laser treatment alone (293 eyes), $0.5 \mathrm{mg}$ ranibizumab + prompt laser photocoagulation (187 eyes), $0.5 \mathrm{mg}$ ranibizumab + deferred laser (at least 24 weeks, 188 eyes), or intravitreal triamcinolone $4 \mathrm{mg}+$ prompt laser (186 eyes).

At the one-year examination, the mean change in visual acuity letter score with respect to the baseline value showed a statistically significant improvement in the ranibizumab + prompt laser group $(+9 \pm 11$ letters, $P<0.001)$ and ranibizumab + deferred laser group $(+9 \pm 12, P<0.001)$ but not in the triamcinolone + prompt laser group $(+4 \pm 13$, $P=0.31)$ compared with the laser group $(+3 \pm 13)$. The study reported a similar reduction of diabetic macular edema in patients treated with triamcinolone or ranibizumab injections and a greater reduction in the patient group treated with laser photocoagulation alone.

Over the two years of follow-up, a different correlation between visual acuity change and retinal thickness was observed in each group. A progressive reduction in mean central subfield thickness was noted in the laser group during the 24 months of follow-up; however, the mean change in visual acuity did not continue to increase from the one-year visit to the two-year visit, as noted during the first year of follow-up.

In the triamcinolone + laser group, during the first year of follow-up, an improvement of visual function was associated with a significant reduction in central subfield thickness, whereas from the one-year to two-year examination, the mean central subfield thickness increased in parallel with visual acuity reduction. The ranibizumab groups showed a visual acuity improvement associated with a central subfield thickness reduction from baseline to the 12-month visit. In the following period, the optical coherence tomography results remained relatively stable up to the 24-month examination and paralleled the visual acuity outcomes during this time. Intraocular hypertension and cataract surgery were more frequently noted in the triamcinolone + prompt laser group in comparison with groups receiving ranibizumab + laser or laser alone. This trial confirms the promising preliminary results of ranibizumab in the treatment of diabetic macular edema and suggests that combined therapy might offer a more efficient approach, considering the multifactorial pathogenesis of the disorder. Table 1 summarizes the results of the major randomized clinical trials of ranibizumab.

\section{Bevacizumab and ranibizumab}

Recently, a new study ${ }^{23}$ compared the effects of bevacizumab and ranibizumab on visual acuity and macular thickness in eyes affected by diabetic macular edema. The study enrolled 29 patients who received one single intravitreal injection of bevacizumab followed at least six months later by one single injection of ranibizumab. The study demonstrated how the two antiangiogenic factors are able to reduce macular thickness (from $411 \mu \mathrm{m}$ to $373 \mu \mathrm{m}$ at follow-up week 6 after bevacizumab injection and from $428 \mu \mathrm{m}$ to $279 \mu \mathrm{m}$ at follow-up week 6 after ranibizumab injection), and improve visual acuity (from 59 ETDRS letters to 61.5 ETDRS letters at follow-up week 6 after bevacizumab injection and from 53 ETDRS letters to 66 ETDRS letters at follow-up week 6 after ranibizumab injection). Unfortunately, this study is characterized by a short follow-up period and a small number of enrolled patients.

\section{Safety and complications}

The MARINA ${ }^{24}$ and ANCHOR ${ }^{25,26}$ trials in neovascular age-related macular degeneration support the safety of intravitreal ranibizumab, and show no increase in systemic adverse effects. Pooled one-year safety data from PIER, ${ }^{27}$ MARINA, and ANCHOR show an increased rate of vascular events $(2.1 \%$ rate of myocardial infarction and stroke) in the ranibizumab arms versus the control group (1.1\%). These differences may be clinically irrelevant, given the two-year safety data. Ocular adverse effects were rare, and similar to rates reported for intravitreal bevacizumab and pegaptanib.

The READ-2 study reported a single case of severe adverse events. One patient died of a cerebral vascular accident six weeks after the first ranibizumab injection. This event was considered unrelated to ranibizumab because of pre-existing cardiovascular disease and because a long period had elapsed between the injection and the vascular event. There were no statistically significant differences in mean systolic and diastolic blood pressure values between the groups. Ocular adverse events included vitreous hemorrhages in eight patients. ${ }^{13,14}$

The RESOLVE study ${ }^{17}$ showed no imbalances in the rates of ocular and nonocular severe adverse effects or adverse effects between patients receiving ranibizumab compared 
Table I Comparative analyses of ranibizumab studies

\begin{tabular}{|c|c|c|c|c|c|c|c|}
\hline \multirow[t]{2}{*}{ Study } & & \multicolumn{3}{|c|}{12 months } & \multicolumn{3}{|c|}{24 months } \\
\hline & & $\begin{array}{l}\text { Letters } \\
\text { gained }\end{array}$ & $\begin{array}{l}\text { Percentage } \\
\text { gaining } 3 \text { lines }\end{array}$ & $\begin{array}{l}\text { Mean CRT } \\
\text { reduction }(\mu \mathrm{m})\end{array}$ & $\begin{array}{l}\text { Letters } \\
\text { gained }\end{array}$ & $\begin{array}{l}\text { Percentage } \\
\text { gaining } 3 \text { lines }\end{array}$ & $\begin{array}{l}\text { Mean CRT } \\
\text { reduction }(\mu \mathrm{m})\end{array}$ \\
\hline \multirow[t]{3}{*}{ READ-2 } & Ranibizumab $0.2 \mathrm{mg}$ & & & & 7.70 & 24 & \\
\hline & Laser & & & & -5.10 & 18 & \\
\hline & Combination & & & & 6.80 & 26 & \\
\hline \multirow[t]{3}{*}{ RESOLVE } & Ranibizumab $0.3-0.6 \mathrm{mg}$ & 9.2 & 18 & 200.7 & & & \\
\hline & Ranibizumab $0.5-1 \mathrm{mg}$ & 6.4 & 15 & 187.6 & & & \\
\hline & Sham & -0.1 & 5 & 48.4 & & & \\
\hline \multirow[t]{3}{*}{ RESTORE } & Ranibizumab $0.5 \mathrm{mg}$ & 6.1 & 22.6 & 118.7 & & & \\
\hline & Combination & 5.9 & 22.9 & 128.3 & & & \\
\hline & Laser & 0.8 & 8.2 & 61.3 & & & \\
\hline \multirow[t]{3}{*}{ RISE } & Lucentis $0.3 \mathrm{mg}$ & & & & & 18.1 & \\
\hline & Lucentis $0.5 \mathrm{mg}$ & & & & & 44.8 & \\
\hline & Sham & & & & & 39.2 & \\
\hline \multirow[t]{3}{*}{ RIDE } & Lucentis $0.3 \mathrm{mg}$ & & & & & 12.3 & \\
\hline & Lucentis $0.5 \mathrm{mg}$ & & & & & 33.6 & \\
\hline & Sham & & & & & 45.7 & \\
\hline \multirow[t]{4}{*}{ DRCRnet } & Sham + prompt laser & 3 & 15 & 102 & 3 & 18 & 138 \\
\hline & Ranibizumab + prompt laser & 9 & 30 & 131 & 7 & 29 & $|4|$ \\
\hline & Ranibizumab + deferred laser & 9 & 28 & 137 & 9 & 28 & 150 \\
\hline & Triamcinolone + prompt laser & 4 & 21 & 127 & 2 & 22 & 107 \\
\hline
\end{tabular}

Abbreviations: CRT, central retinal thickness; DRCTnet, Diabetic Retinopathy Clinical Research Network.

with sham injections. The proportion of patients with ocular severe adverse effects in the study eye was comparable between the treatment arms. Most of the severe adverse effects were nonocular in origin (ranibizumab 14 [13.7\%] and sham eight [16.3\%]). Endophthalmitis occurred in two patients out of the 102 receiving intravitreal ranibizumab injection. Also, the rate of subjects reporting nonocular adverse effects was comparable between the ranibizumab and sham arms, ie, $62.7 \%$ and $65.3 \%$, respectively. In the RESTORE study, ${ }^{18}$ no cases of endophthalmitis were reported. Increased intraocular pressure was reported for one patient each in the ranibizumab arms. Ranibizumab monotherapy or combined with laser was not associated with an increased risk of cardiovascular or cerebrovascular events in this study.

Further, the DRCRnet study reported all complications collected during the two-year follow-up period. ${ }^{21}$ Three cases of endophthalmitis were described following ranibizumab injection, with an incidence of $0.08 \%$, and one case of inflammatory pseudoendophthalmitis $(0.5 \%)$ was reported. For all groups of patients enrolled in the study, there were no statistically significant differences for the incidence of systemic adverse events ( $3 \pm 3$ events in the sham group, $3 \pm 3$ events in the two ranibizumab groups, and $3 \pm 4$ events in the triamcinolone group). The authors also reported a single case of progression of tractional retinal detachment occurring in the ranibizumab + deferred laser group.

\section{Conclusion}

The advent of intravitreal anti-VEGF drugs has opened up a new era in the management of diabetic macular edema. While focal/grid treatment remains a reference for the treatment of diabetic macular edema and is supported by evidence provided by large-scale studies, the use of anti-VEGF substances such as ranibizumab in clinical practice has shown encouraging results. Most of the studies reported in this review were well designed clinical trials with the objective of demonstrating both the therapeutic effect of ranibizumab and data regarding its safety (RESOLVE, RESTORE, DRCRnet, RIDE, and RISE). However, only larger trials can consolidate routine clinical use of anti-VEGF drugs, with the objective of creating standard guidelines for the management of diabetic macular edema. Another aspect that must be highlighted is the efficacy of anti-VEGF drugs over a long follow-up period. Most controlled studies focus on one-year or two-year results, so long-term results are unavailable. It would be of foremost importance to demonstrate that anti-VEGF drugs are able to provide therapeutic effects over a long period of time, and to compare these effects with those of laser treatment, which is characterized by a prolonged therapeutic effect that most likely is more efficient many years after its employment. The use of combination therapy, including ranibizumab and focal/grid laser treatment, shows encouraging results, as demonstrated by the READ-2, RESOLVE, RESTORE, and DRCRnet studies, and must also be evaluated over a 
long time span. The clinical trials to date have demonstrated an adequate safety profile for ranibizumab, although longterm analysis of systemic and ocular side effects is needed. Therefore, it is important to control patients who undergo intravitreal injections of antiangiogenic drugs for diabetic macular edema carefully. Although severe ocular adverse events are unusual and rarely reported, the limited experience relating to the use of this new class of drugs requires all ophthalmologists to select patients carefully and to schedule strict follow-up examinations in order to detect short-term and long-term side effects promptly.

\section{Disclosure}

FB is a consultant for Novartis, Allergan, Pfizer, Alcon, Bayer, and Thea.

\section{References}

1. Early Treatment Diabetic Retinopathy Study Group. Photocoagulation for diabetic macular edema: ETDRS report no. 4. Int Ophthalmol Clin. 1987;27:265-272.

2. Early Treatment Diabetic Retinopathy Study Group. Photocoagulation for DME: Early treatment diabetic retinopathy study report number 1. Arch Ophthalmol. 1985;103:1796-1806.

3. Bandello F, Parodi MB, Lanzetta P, et al. Diabetic macular edema. Dev Ophthalmol. 2010;47:73-110.

4. ETDRS Research Group. Treatment techniques and clinical guidelines for photocoagulation of diabetic macular edema. Early Treatment Diabetic Retinopathy Study Report Number 2. Early Treatment Diabetic Retinopathy Study Research Group. Ophthalmology. 1987;94: 761-774.

5. Neufeld G, Cohen T, Gengrinovitch S, Poltorak Z. Vascular endothelial growth factor (VEGF) and its receptors. FASEB J. 1999;13:9-22.

6. Grant MB, Afzal A, Spoerri P, Pan H, Shaw LC, Mames RN. The role of growth factors in the pathogenesis of diabetic retinopathy. Expert Opin Investig Drugs. 2004;13:1275-1293.

7. Plate KH, Breier G, Weich HA, Risau W. Vascular endothelial growth factor is a potential tumour angiogenesis factor in human gliomas in vivo. Nature. 1992;359:845-848.

8. Shweiki D, Itin A, Soffer D, Keshet E. Vascular endothelial growth factor induced by hypoxia may mediate hypoxia-initiated angiogenesis. Nature. 1992;359:843-845.

9. Aiello LP, Avery RL, Arrigg PG, et al. Vascular endothelial growth factor in ocular fluid of patients with diabetic retinopathy and other retinal disorders. N Engl J Med. 1994;331:1480-1487.

10. Gardner TW, Antonetti DA, Barber AJ, LaNoue KF, Levison SW. Diabetic retinopathy: More than meets the eye. Surv Ophthalmol. 2002; 47 Suppl 2:S253-S262.

11. Chun DW, Heier JS, Topping TM, Duker JS, Bankert JM. A pilot study of multiple intravitreal injections of ranibizumab in patients with center-involving clinically significant diabetic macular edema. Ophthalmology. 2006;113:1706-1712.

Clinical Ophthalmology

\section{Publish your work in this journal}

Clinical Ophthalmology is an international, peer-reviewed journal covering all subspecialties within ophthalmology. Key topics include: Optometry; Visual science; Pharmacology and drug therapy in eye diseases; Basic Sciences; Primary and Secondary eye care; Patient Safety and Quality of Care Improvements. This journal is indexed on Submit your manuscript here: http://www.dovepress.com/clinical-ophthalmology-journal
12. Nguyen QD, Tatlipinar S, Shah SM, et al. Vascular endothelial growth factor is a critical stimulus for diabetic macular edema. Am J Ophthalmol. 2006;142:961-969.

13. Nguyen QD, Shah SM, Heier JS, et al; READ-2 Study Group. Primary end point (six months) results of the Ranibizumab for Edema of the mAcula in Diabetes (READ-2) Study. Ophthalmology. 2009;116:2175-2181. e1

14. Nguyen QD, Shah SM, Khwaja AA, et al. READ-2 Study Group. Two-year outcomes of the ranibizumab for edema of the mAcula in diabetes (READ-2) study. Ophthalmology. 2010;117:2146-2151.

15. Genentech. Two pivotal Phase III Lucentis studies showed patients with diabetic macular edema experienced significant improvements in vision and fewer developed more advanced retinopathy. Available from: http://www.gene.com. Accessed June 28, 2011.

16. Wolf S, Massin P, Bandello F, et al; RESOLVE Study Group. Safety and efficacy of ranibizumab treatment in patients with diabetic macular edema: 12-month results of the RESOLVE Study. Presented at the Association for Research in Vision and Ophthalmology meeting May 3-7, 2009, Fort Lauderdale, FL.

17. Massin P, Bandello F, Garweg JG, et al. Safety and efficacy of ranibizumab in diabetic macular edema (RESOLVE study): A 12-month, randomized, controlled, double-masked, multicenter phase II study. Diabetes Care. 2010;33:2399-2405.

18. Mitchell P, Bandello F, Schmidt-Erfurth U, et al. The RESTORE study: Ranibizumab monotherapy or combined with laser versus laser monotherapy for diabetic macular edema. Ophthalmology. 2011;118: 615-625.

19. Massin P, Audren F, Haouchine B, et al. Intravitreal triamcinolone acetonide for diabetic diffuse macular edema: Preliminary results of a prospective controlled trial. Ophthalmology. 2004;111:218-224.

20. Gillies MC, Sutter FK, Simpson JM, Larsson J, Ali H, Zhu M. Intravitreal triamcinolone for refractory diabetic macular edema: Two-year results of a double-masked, placebo-controlled, randomized clinical trial. Ophthalmology. 2006;113:1533-1538.

21. Elman MJ, Aiello LP, Beck RW, et al. Diabetic Retinopathy Clinical Research Network. Randomized trial evaluating ranibizumab plus prompt or deferred laser or triamcinolone plus prompt laser for diabetic macular edema. Ophthalmology. 2010;117:1064-1077.

22. Elman MJ, Bressler NM, Qin H, et al. Expanded 2-year follow-up of ranibizumab plus prompt or deferred laser or triamcinolone plus prompt laser for diabetic macular edema. Diabetic Retinopathy Clinical Research Network. Ophthalmology. 2011;118:609-614.

23. Ozturk BT, Kerimoglu H, Bozkurt B, Okudan S. Comparison of intravitreal bevacizumab and ranibizumab treatment for diabetic macular edema. J Ocul Pharmacol Ther. 2011;27:373-377.

24. Rosenfeld PJ, Brown DM, Heier JS, et al; MARINA Study Group. Ranibizumab for neovascular age-related macular degeneration. NEngl J Med. 2006;355:1419-1431.

25. Brown DM, Kaiser PK, Michels M, et al. Ranibizumab versus verteporfin for neovascular age-related macular degeneration. $N$ Engl J Med. 2006;355:1432-1444.

26. Brown DM, Michels M, Kaiser PK, Heier JS, Sy JP, Ianchulev T. Ranibizumab versus verteporfin photodynamic therapy for neovascular age-related macular degeneration: Two-year results of the ANCHOR study. Ophthalmology. 2009;116:57-65.

27. Abraham P, Yue H, Wilson L. Randomized, double-masked, shamcontrolled trial of ranibizumab for neovascular age-related macular degeneration: PIER study year 2. Am J Ophthalmol. 2010;150:315-324.

\section{Dovepress}

PubMed Central and CAS, and is the official journal of The Society of Clinical Ophthalmology (SCO). The manuscript management system is completely online and includes a very quick and fair peer-review system, which is all easy to use. Visit http://www.dovepress.com/ testimonials.php to read real quotes from published authors. 